\title{
Non-obstruktif azoospermide micro-TESE: önemli yenilikler
}

\author{
Micro-TESE in non-obstructive azoospermia: Major innovations
}

\author{
Kasım Emre Ergün®, Barıș Altay®
}

\section{öz}

Non-obstruktif azoospermili erkeklerde sperm elde etme için altın standart yöntem olarak uygulanan mikrodiseksiyon TESE (micro-TESE) yönteminde, ilk tanımlandığı 1998 yılından bugüne, sperm elde etme oranlarında önemli artışlar olmuștur. Preoperatif olarak micro-TESE başarısını öngörebilmek için özellikle ultrasonografi, testis spektroskopisi, seminal plazma ekstrasellüler vezikülleri gibi konularda güncel çalışmalar yapılmaktadır. Aynı zamanda da, cerrahi sırasında daha az doku hasarı ile daha başarılı sonuçlara ulaşmak için mini-insizyon micro-TESE, longitudinal tunika albuginea insizyonu gibi yeni teknikler geliştirilmeye çalışılmaktadır. Sperm toplanması aşamasında daha verimli sonuçlar için mikroakışkan sistemler gibi yeni teknolojilerin micro-TESE'de kullanımı umut verici gözükmektedir.

Anahtar Kelimeler: micro-TESE, spektroskopi, mini-insizyon, mikroakışkan

\section{GíRiș}

Azoospermi, tüm erkeklerin \%1'inde görülmekle birlikte infertil erkeklerde bu oran \%10-15'e ulaşmaktadır. Azoospermi olgularının \%60-70'ini non-obstruktif azoospermi (NOA), \%30-40'1nı da obstruktif azoospermi olguları oluşturmaktadır. ${ }^{[1,2]}$ NOA'lı erkeklerde hipospermatogenez, matürasyon arresti veya Sertoli cell only sendromu histopatolojileri ile karakterize spermatogenik yetmezlik bulunmaktadır ve bu erkekler günümüzde, cerrahi sperm toplama yöntemleri ile birlikte uygulanan yardımcı üreme teknikleri ile çocuk sahibi olabilmektedir.

İlk kez 1995 yilında, NOA'lı olgularda testiküler sperm ekstraksiyonu (TESE) ile elde edilen testiküler sperm, in vitro fertilizasyon-intrasitoplazmik sperm injeksiyonu

Ege Üniversitesi Tıp Fakültesi, Üroloji Anabilim Dalı, İmir, Türkiye

Yazışma Adresi/ Correspondence:

Uzm. Dr. Kasım Emre Ergün

Ege Üniversitesi Tıp Fakültesiüroloji Anabilim Dalı İzmir, Türkiye

Tel: $\quad+905057350019$

E-mail: kasimemreergun@gmail.com

Geliş/ Received: $\quad 20.05 .2021$

Kabul/ Accepted: $\quad 25.05 .2021$

\section{ABSTRACT}

In the microdissection TESE (micro-TESE) method, which is used as the gold standard method for sperm retrieval in men with nonobstructive azoospermia, since 1998, when it was first defined, there has been a significant increase in sperm retrieval rates. In order to predict the success of micro-TESE preoperatively, up-to-date studies are carried out, especially on ultrasonography, testicular spectroscopy, seminal plasma extracellular vesicles. At the same time, new techniques such as mini-incision micro-TESE and longitudinal tunica albuginea incision are being developed in order to achieve more successful results with less tissue damage during surgery. The use of new technologies such as microfluidic systems in micro-TESE seems promising for more efficient results at the sperm sorting stage.

Keywords: micro-TESE, spectroskopy, mini-incision, microfluidic
(IVF-ICSI) için kullanılmıştır. ${ }^{[3]} 1998$ yılına gelindiğinde ise Schlegel ve ark. tarafindan mikrodiseksiyon TESE (micro-TESE) tanımlanarak erkek infertilite tedavisinde adeta bir devrim meydana gelmiştir. ${ }^{[4]}$ Micro-TESE ile tekli ya da multibiyopsi TESE'nin karşılaştırıldığı sistematik derlemelerde, micro-TESE ile sperm elde etme oranlarının \%1520 daha fazla olduğu ortaya konulmuştur. ${ }^{[5,6]}$ Günümüzde micro-TESE, NOA'lı erkeklerde sperm elde etme için altın standart yöntem olarak kabul edilmektedir. ${ }^{[7]}$

Bilindiği gibi ICSI için fertilizasyonu sağlayabilecek tek bir sperme ihtiyaç vardır ve özünde NOA'da micro-TESE yöntemini geliştirmek için yapılan tüm çalışmalar bu spermi elde edebilmek içindir. Bu derlemede, NOA'lı olgularda uygulanan micro-TESE yönteminde son yıllarda tarif edilen yeniliklerin incelenmesi amaçlanmıştır.

\section{MICRO-TESE ÖNCESI DEĞERLENDIRMEDE VE CERRAHI TEKNIKTEKI GELIȘMELER}

Tekrarlanan başarısız micro-TESE uygulamaları, testiküler atrofi ve serum androjen seviyelerinde azalmanın yanı sıra çiftlerde psikolojik sorunlara da neden olabilmektedir. Bu 
nedenle, micro-TESE başarısını etkileyen faktörlerin değerlendirilmesi yıllardır önemle üzerinde çalışılan konulardandır. Yaş, testis volümü, serum $\mathrm{FSH}$, inhibin ve testosteron düzeyleri, testiküler histoloji, Y kromozom mikrodelesyonları gibi micro-TESE başarısını öngörebilecek faktörler yıllar içerisinde birçok çalışmada değerlendirilmiştir. ${ }^{[8-10]}$ Testis histopatolojisi ve AZF Y kromozom delesyonu başarıyı belirlemede en etkin faktörler olarak ön plana çıkmaktadır. Öte yandan, tüm bu faktörlerin klinik pratikte preoperatif olarak sperm elde etmeyi öngörmedeki rolleri kısıtlıdır.

Literatürde micro-TESE'de sperm elde etmeyi öngörmede yardımcı olacak preoperatif faktörlerle ilgili güncel çalışmalar bulunmaktadır. Nariyoshi ve ark. çalışmalarında, ilk kez preoperatif gri-skala ultrason (US) ile seminifer tübül boyutlarının değerlendirilmesinin micro-TESE başarısını öngörmedeki rolünü incelemişlerdir. Gri-skala görüntüler JPEG formatında bilgisayara aktarılarak seminifer tübül morfolojileri değerlendirilmiştir. Transvers planda gri-skala skrotal US ile testisin üst, orta ve alt bölümlerinde 6 görüntü, $\% 96$ kontrast ve $\% 50$ parlaklık ile incelenmiş ve sonra parlaklık yavaş yavaş \%30'a indirilerek seminifer tübül çaplarındaki heterojenite bu şekilde ortaya konmuştur.806 NOA’lı erkeği içeren bu çalışmada, sperm elde etme oranı, tübül çapı 300 $\mu \mathrm{m}$ olanlarda $\% 86,9,250 \mu \mathrm{m}$ olanlarda ise $\% 50,5$ olarak bulunmuş ve testiküler ultrasondaki gri-skala görüntülerin micro-TESE'de sperm elde etme için prediktör olduğu sonucuna varılmıştır. ${ }^{[11]}$ Zhang ve ark., kontrastlı skrotal US

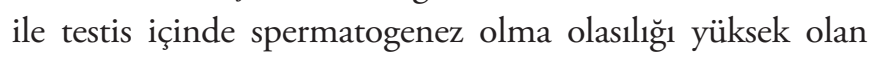
alanların tespit edilip edilemeyeceklerini araştırmışlardır.120 NOA'lı olgu içeren bu çalışmada, kontrast madde $(2,4 \mathrm{ml}$ sülfür heksaflorid mikrokabarcık) uygulamasından sonra ilk kabarcığın testise ulaştığı zaman (AT) <27 s, görüntü yoğunluğunun maksimuma ulaştığı zaman (TTP) $<45$ s ve pik yogunluk değerleri $(\mathrm{PI})>11 \mathrm{~dB}$ ise testiste spermatogenezden daha zengin alanlara ulaşlabildiği rapor edilmiştir. ${ }^{[12]}$

Ntorkou ve ark. çalışmasında, canlı dokuların biyokimyasal ve moleküler bileşimi hakkında bilgi sağlayan non-invaziv bir görüntüleme yöntemi olan proton manyetik rezonans spektroskopinin (1H-MRS) NOA'lı olgularda micro-TESE başarısını preoperatif olarak öngörmedeki rolü incelenmiştir. Testis spektroskopi, manyetik rezonans spektroskop ile ince kesitlerde aksiyel ve koronal planlarda kolin, myoinozitol, kreatin, glutamat, lipid ve laktat gibi farklı metabolitlerin spektrumda incelenmesi ile uygulanan yöntemdir. 49 NOA'l olgu ve 50 kontrol grubunun olduğu bu prospektif çalışmada, glutamat yüksekliği micro-TESE başarısız hastalarda daha sık bulunurken, kolin (membran sentezi ve hücresel proliferasyonda rol alır) ve miyoinozitol (seminifer tübül ozmo-regülasyonunda etkili) yüksekliğinde micro-TESE ile sperm elde etme başarısının yüksek olduğu bulunmuştur. ${ }^{[13]}$ Çelik ve ark., 18 olguyu içeren çalışması sonucunda, micro-TESE'de sperm elde etme şansı ile yüksek kolin piki arasında güçlü bir ilişki saptanmış ve artmış kolin sinyal yoğunluğunun micro-TESE başarısını öngörmede yüksek duyarlılığa sahip olduğu belirtilmiştir. ${ }^{[14]}$

Preoperatif olarak micro-TESE başarısını öngörme amacıyla son dönemde üzerinde çalışılan moleküllerden birisi de seminal plazma ekstrasellüler veziküllerindeki küçük RNA'larıdır. Ekstrasellüler veziküller (EV) (eksozomlar ya da mikroveziküller olarak da bilinirler), normal veya patolojik durumlarda birçok hücre tipi tarafından ekstrasellüler çevreye salınan ve intersellüler bağlantıları yönettikleri düşünülen yapılardır. Çeşitli çalışmalarda EV'deki küçük RNA'ların, sperm matürasyonu, kapasitasyon, akrozom reaksiyonu ve fertilizasyonda önemli rolleri olabileceği ifade edilmiştir. ${ }^{[15]} \mathrm{Bu}$ bulgular eşliğinde, seminal plazma EV'deki küçük RNA'ların üreme sistemini direkt ve spesifik olarak yansıtabileceği ve de spermatogenik fonksiyonu göstermede aday belirteçler olabileceği düşünülmüştür. piRNA ailesi, seminal plazma EV'nin önemli içeriklerinden birisidir. Chen ve ark. çalışmasında, seminal plazma EV'deki piRNA'ların testisteki spermatogenik fonksiyonu yansıtan belirteçler olabileceği hipotezi ile NOA'lı olgularda testiste sperm varlığını öngörebilecek bir model geliştirilmeye çalışılmıştır. NOA'lı olgularda kontrol grubuna göre seminal plazma EV-piRNA ekspresyonun azaldığı gösterilmiştir. Sonuç olarak, seminal plazma EV-piRNA analizi NOA'lı olgularda micro-TESE başarısını non-invaziv olarak öngörebilecek bir yöntem olarak önerilmiştir. ${ }^{[16]}$

Micro-TESE'de mikroskop altında daha büyük ve opak gözüken seminifer tübüllerde aktif spermatogenez bulunma olasıllğıının fazla olduğu düşünülmektedir. Geçmiş yıllarda yüksek büyütme altında seminifer tübül kalibrasyon paternlerinin değerlendirilmesine değinen çeşitli çalışmalar yayımlanmıştır. Ancak bu paternlerin NOA'lı hastalarda sperm elde etme başarısını öngörmedeki tanısal doğruluğu kanıtlanamamıştır. Caroppo ve ark. çalışmasında, micro-TESE sırasında operatif mikroskoptaki en yüksek büyütme $(\times 24)$ ile seminifer tübül paternleri değerlendirilmiş ve dilate tübüller, hafif dilate tübüller ve dilate olmayan tübüller olarak üç grup halinde incelenmiştir. Çalışma sonucunda, dilate tübüllerde başarılı sperm elde etme oranı $\% 90$ bulunurken, dilate olmayan tübüllerde $\% 7$ olarak bulunmuştur. Bu sonuçlar eşliğinde, NOA'da micro-TESE esnasında yüksek büyütme altında incelenen seminifer tübül kalibrasyon paternlerinin, micro-TESE başarısını öngörmede intraoperatif prediktör faktör olduğu ifade edilmiştir. ${ }^{[17]}$

Bilindiği gibi, NOA'lı olgularda spermatogenez testisin her bölgesinde uniform bir şekilde değil de adacıklar halinde 
yamasal olarak meydana gelebilmektedir. Çeşitli çalışmalarda, testiste mümkün olan en geniş alanı incelemenin uygun tübülleri bulmak ve dolayısıyla sperm elde etme olasılığını arttırmak için faydalı olabileceği belirtilmiştir. Ichioka ve ark., hangi insizyonlar ile incelenen testis alanının daha fazla olduğunu ölçmek için matematiksel üç boyutlu simülasyon analizi geliştirmişlerdir. Bu çalışmada, uygun tübülleri bulma olasılığı toplam parankimal kesi yüzey alanına bağlı bulunmuştur. Bu modelleme ile tunika albugineaya yapılan longitudinal insizyon ve ardindan parankime uygulanan transvers dilimleme insizyonları ile maksimum yüzey alanının incelenebildiği gösterilmiştir. 102 hastada bu yeni yöntemi, 56 hastada ise micro-TESE'de tunika albugineaya klasik olarak yapılan vertikal insizyonu uygulamışlar ve yeni yöntemde daha yüksek sperm elde etme oranı (\%45'e karşılık \%29) bulmuşlardır. Parankimdeki intratestiküler arterlerin mikroskop yardımıyla net olarak korunabildiği, hematom, yara yeri enfeksiyonu ve testosteron kaybı açısından bu teknik ile fark olmadığını ortaya koymuşlardır. ${ }^{[18]}$

Öte yandan, daha az doku diseksiyonu ve dolayısıyla daha az inflamasyon ve skar oluşumu hedefi ile micro-TESE'deki konvansiyonel ekvatoryal insizyona alternatif arayan çalışmalar da bulunmaktadır. Almajed ve ark. çalışmasında, mini tunika albuginea insizyonu ile uygulanan modifiye micro-TESE tekniği kullanılmıştır. Bu teknikte yaklaşık 1 cm'lik transvers ekvatoryal tunika albuginea insizyonu (mini-insizyon) yapılıp testiküler parankim operatif mikroskop altında x10-30 büyütmede incelenmekte, spermatozoa ya da dilate tübül görülmediğinde insizyon her iki tarafa doğru 1-1,5 cm uzatılmaktadır. Bu çalışmada, mini-insizyon micro-TESE yönteminin uygulandığı $74 \mathrm{NOA}^{\prime} \mathbf{l}_{\text {ı }}$ olguda sperm elde etme oranı \%25,6 bulunmuş, mini-insizyonun başarısız olduğu olgularda uygulanan konvansiyonel micro-TESE ile toplam sperm elde etme oranı $\% 48$ 'e ulaşmıştır. Bu sonuçlarla, mini-insizyon micro-TESE, daha kısa operasyon süresi ve daha az doku hasarı ile uygun olgularda tercih edilebilir yöntem olarak sunulmaktadır. ${ }^{[19]} \mathrm{Li}$ ve ark. çalışmasında ise orşidopeksi öyküsü olan 20 NOA'lı olguya aşamalı mini-insizyon micro-TESE uygulanmış ve 10 hastada mini-insizyon ile sperm elde edilmiştir. Cerrahi sonrası yapışıklıkların olduğu bu grup hastalarda, bu teknik ile daha kısa sürede, daha az komplikasyon ile başarılı şekilde sperm elde edildiği bildirilmiştir. ${ }^{[20]}$

\section{SPERM TOPLANMASINDAKI GELISTMELER}

Micro-TESE ile alınan dokulardan spermlerin ayrıştırılması yoğun emek gerektiren, verimliliği düşük ve pahalı bir süreçtir. Seminifer tübüllerden spermlerin ayrıştırılması için iğne, makas ya da anjiokateterler ile dokular parçalanmakta ve ardından kollajenazlar ve diğer doku bozucu yöntemlerle ekstrasellüler matriks sıvilaştırılarak optik mikroskopta incelenmektedir. Güncel pratikte kullanılan bu yöntemlerle sperm ayrıştırılması işlemi esnasında yorgunluk, kişisel yetersizlikler gibi insana bağlı faktörlerden etkilenme ve işlem sırasında sperm hasarı oluşumu gibi önemli sorunlar bulunmaktadır. ${ }^{[21]}$ micro-TESE sonrası sperm elde etmeyi arttırabilecek çeşitli yeni teknolojiler üzerinde çalışılmaktadır. Bu yeni teknolojiler içerisinde, hücreleri ayırmak için küçük sıvı akışları kullanan mikroakışkanlar (dielektroforez ve sıkışmış akım dâhil), manyetik-aktif hücre ayrıştırılması (MACS) ve florasan-aktif hücre ayrıştırılması (FACS) yöntemleri öne çıkmaktadır.

Mikroakışkanlar, ayrıştırma için sıvıların nano ya da mikro ölçekli manipülasyonudur. Mikroakışkanlar, biyokimyasal madde kullanımı, yıkama ve santrifüjle ilişkili reaktif oksijen radikali oluşumu ve uzamış kollajenaz maruziyeti gibi klasik sperm ayrıştırma yöntemlerinin zararlı etkilerinden kaçınmayı sağlamaktadır. ${ }^{[22]}$ Samuel ve ark., çalışmaların$\mathrm{da}$, testis biyopsilerinden spermleri ayrıştırmak için geliştirdikleri mikroakışkan sistem ile konvansiyonel tekniklere göre dakikada 8,88 kat fazla sperm bulunduğu gösterilmiştir. ${ }^{[23]}$ Mikroakışkan teknolojilerin micro-TESE'deki uygulamaları sperm motilitesi ile sınırlı gözükmekle birlikte önümüzdeki süreçte, çeşitli yeni mikroakışkan türevi teknolojilerle non-motil hücrelerin de ayrıştırılması olası gözükmektedir.

Manyetik-aktif hücre ayrıştırılması (MACS), hücre yüzeyindeki antijenlere bağlanan antikor kaplı manyetik tanecikleri kullanan pasif bir ayrıştırma yöntemidir. Hasarlı spermlerden membran dışına fosfolipid fosfatidilserin (PS) açığa çıkmaktadır. Annexin V ise PS'ye yüksek afinite gösteren ve sağlam spermlere bağlanmayan bir moleküldür. MACS yönteminde, hücreler sütun içerisinden geçerken PS eksprese edenler mıknatıs özellikli mikrotaneciklerle konjuge edilmiş Annexin V'e bağlanırlar ve bunlar yüksek manyetik alana girdiklerinde sütun içerisinde kalırlar. Sonuçta sağlam hücreler serbestçe sütundan geçip ayrışt1rilır. ${ }^{[24]}$

Florasan-aktif hücre ayrıştırılması (FACS), hücre ayrıştırması için hücre yüzey antijenlerini tanımlayacak bir florofor etiketlemeye gereksinim duyulan aktif bir ayrıştırma yöntemidir. Öncelikle hücreler florasan antikorlar ya da DNA etiketleri ile işaretlenir ve sonrasında laserle geçen bir sıvı akımına yerleştirilir. ${ }^{[25]}$ Mittal ve ark., çalışmalarında, micro-TESE örneklerinden non-motil spermlerin ayrışt1rılmasında FACS yönteminin başarı ile uygulandığı gösterilmiştir. ${ }^{[26]}$ Devam eden araştırmalarda, bu ayrıştırma yöntemine bağlı sperm DNA fragmantasyonu oluşumu ile ilgili kaygılar bulunmaktadır. 
$\mathrm{Bu}$ yöntemler karşılaştırıldığında mikroakışkan uygulamalar daha umut verici gözükmektedir. Mikrokanal t1kanmalarının önlenmesine yönelik yapılacak gelecekteki çalışmalar, micro-TESE örneklerinden non-motil sperm elde edilmesinde mikroakışkan sistemlerin kullanılmasını hızlandıracaktır.

\section{SONUÇ}

Micro-TESE, NOA'lı olguların tedavisinde devrimsel bir yöntem olmakla birlikte, hali hazırda sperm elde etmeyi öngörmede yardımcı olacak preoperatif faktörler kısıtlıdır. Şüphesiz, preoperatif olarak sperm üretilen alanları tanımlayacak görüntüleme tekniklerinin geliştirilmesi, micro-TESE yöntemini daha da ilerletecektir.

Yıllar içerisinde micro-TESE tekniklerinde meydana gelen gelişmeler, NOA'lı olgularda sperm elde etme oranlarını önemli ölçüde arttırmıştır. Bu ilerlemeye rağmen, laboratuar aşamasında testis örneklerinden canlı sperm saptanması zaman alıcı ve oldukça emek isteyen bir süreçtir. Sperm ayrıştırma ile ilgili yeni teknolojilerin kullanımı bu konudaki verimliliği arttıracak ve ayrıca nadir spermlerin tanımlanmasını, belki de optimal sperm seçimi ile gebelik ve canlı doğum oranlarının artmasını sağlayabilecektir.

\section{Hakem Değerlendirmesi}

Dış bağımsız.

Çıkar Çatışması

Yazarlar çıkar ilişkisi olmadığını beyan etmişlerdir.

\section{Finansal Destek}

Herhangi bir mali destek alınmamıştır.

\section{Peer-review}

Externally peer-reviewed.

Conflict of Interest

No conflict of interest was declared by the authors.

Financial Disclosure

No financial support has been received.

\section{KAYNAKLAR}

1. Schlegel PN. Causes of azoospermia and their management. Reprod Fertil Dev 2004;16:561-72. [CrossRef]

2. Kumar R. Medical management of non-obstructive azoospermia. Clinics (Sao Paulo) 2013;68:75-9. [CrossRef] https://doi. org/10.6061/clinics/2013(Sup01)08

3. Devroey P, Liu J, Nagy Z, Goossens A, Tournaye H, Camus M, et al. Pregnancies after testicular sperm extraction and intracytoplasmic sperm injection in non-obstructive azoospermia. Hum Reprod 1995; 10:1457-60. [CrossRef]

4. Schlegel PN, Li PS. Microdissection TESE: Sperm retrieval in non-obstructive azoospermia. Hum Reprod Update 1998;4:439. [CrossRef]

5. Deruyver Y, Vanderschueren D, van der Aa F. Outcome of microdissection TESE compared with conventional TESE in non-obstructive azoospermia: a systematic review. Andrology 2014;2:20-4. [CrossRef]
6. Bernie AM, Mata DA, Ramasamy R, Schlegel PN. Comparison of microdissection testicular sperm extraction, conventional testicular sperm extraction, and testicular sperm aspiration for nonobstructive azoospermia: a systematic review and meta-analysis. Fertil Steril 2015;104:1099-103.e1-3. [CrossRef]

7. Schlegel PN, Sigman M, Collura B, De Jonge CJ, Eisenberg ML, Lamb DJ, et al. Diagnosis and treatment of infertility in men: AUA/ASRM guideline part II. Fertil Steril 2021;115:62-9. [CrossRef]

8. Hopps CV, Mielnik A, Goldstein M, Palermo GD, Rosenwaks Z, Schlegel PN. Detection of sperm in men with y chromosome microdeletions of the $\mathrm{AZFa}, \mathrm{AZFb}$ and $\mathrm{AZFc}$ regions. Hum Reprod 2003;18:1660-5. [CrossRef]

9. Abdel Raheem A, Garaffa G, Rushwan N, De Luca F, Zacharakis E, AbdelRaheem T, et al. Testicular histopathology as a predictor of a positive sperm retrieval in men with non-obstructive azoospermia. BJU Int 2013;111:492-9. [CrossRef]

10. Khelaia A, Saker Z, Tsintsadze O, Managadze L. Nonobstructive azoospermia, follicle-stimulating hormone as a marker of successful sperm retrieval. Georgian Med News 2015;249:34-7. https:// pubmed.ncbi.nlm.nih.gov/26719547/

11. Nariyoshi S, Nakano K, Sukegawa G, Sho T, Tsuji Y. Ultrasonographically determined size of seminiferous tubules predicts sperm retrieval by microdissection testicular sperm extraction in men with nonobstructive azoospermia. Fertil Steril 2020;113:97-104.e2. [CrossRef]

12. Zhang S, Du J, Tian R, Xie S, Li F, Li Z. Assessment of the use of contrast enhanced ultrasound in guiding microdissection testicular sperm extraction in nonobstructive azoospermia. BMC Urol 2018;18:48. [CrossRef]

13. Ntorkou A, Tsili AC, Astrakas L, Goussia A, Panopoulou E, Sofikitis N, Argyropoulou MI. In vivo biochemical investigation of spermatogenic status:1H-MR spectroscopy of testes with nonobstructive azoospermia. Eur Radiol 2020;30:4284-94. [CrossRef]

14. Çelik Ö, Hatırnaz Ş, Erşahin A, Başbuğ A, Yıldırım GY, Özener V, et al. Testis spectroscopy may predict sperm retrieval rate in men with non-obstructive azoospermia undergoing micro-TESE. A pilot study. J Turk Ger Gynecol Assoc 2020;21:70-8. [CrossRef]

15. Siciliano L, Marciano V, Carpino A. Prostasome-like vesicles stimulate acrosome reaction of pig spermatozoa. Reprod Biol Endocrinol 2008;6:5. [CrossRef]

16. Chen H, Xie Y, Li Y, Zhang C, Lv L, Yao J, et al. Outcome prediction of microdissection testicular sperm extraction based on extracellular vesicles piRNAs. J Assist Reprod Genet 2021;38:1429-39. [CrossRef]

17. Caroppo E, Colpi EM, Gazzano G, Vaccalluzzo L, Piatti E, D'Amato G, Colpi GM. The seminiferous tubule caliber pattern as evaluated at high magnification during microdissection testicular sperm extraction predicts sperm retrieval in patients with nonobstructive azoospermia. Andrology 2019;7:8-14. [CrossRef]

18. Ichioka K, Matsui Y, Terada N, Negoro H, Goto T, Ogawa O. Three-dimensional simulation analysis of microdissection testicular sperm extraction for patients with non-obstructive azoospermia. Andrology 2020;8:1214-21. [CrossRef]

19. Almajed W, Alharbi M, Zini A. Use of mini-incision microdissection testicular sperm extraction in men with cryptozoospermia and nonobstructive azoospermia. Andrology 2020;8:1136-42. [CrossRef]

20. Li P, Yao CC, Zhi EL, Xu Y, Wan Z, Jiang YC, et al. Modified stepwise mini-incision microdissection testicular sperm extraction: a useful technique for patients with a history of orchidopexy affected by non-obstructive azoospermia. J Zhejiang Univ Sci B 2020;21:87-92. [CrossRef] 
21. Mangum CL, Patel DP, Jafek AR, Samuel R, Jenkins TG, Aston KI, et al. Towards a better testicular sperm extraction: novel sperm sorting technologies for non-motile sperm extracted by microdissection TESE. Transl Androl Urol 2020;9:206-14. [CrossRef]

22. Rappa KL, Rodriguez HF, Hakkarainen GC, Anchan RM, Mutter GL, Asghar W. Sperm processing for advanced reproductive technologies: Where are we today? Biotechnol Adv 2016;34:57887. [CrossRef]

23. Samuel R, Son J, Jenkins TG, Jafek A, Feng H, Gale BK, et al. Microfluidic System for Rapid Isolation of Sperm From Microdissection TESE Specimens. Urology 2020;140:70-6. [CrossRef]
24. Said TM, Agarwal A, Grunewald S, Rasch M, Glander HJ, Paasch U. Evaluation of sperm recovery following annexin $\mathrm{V}$ magneticactivated cell sorting separation. Reprod Biomed Online 2006;13:336-9. [CrossRef]

25. Komoda T, Matsunaga T. Chapter 6 - Biotechnological Study. In: Komoda T, Matsunaga T, editors. Biochemistry for Medical Professionals. Boston: Academic Press; 2015. p.75-92.

26. Mittal S, Mielnik A, Bolyakov A, Schlegel P, Paduch D. Pd68-01 Pilot Study Results Using Fluorescence Activated Cell Sorting of Spermatozoa from Testis Tissue: A Novel Method for Sperm Isolation after TESE. J Urol 2017;197:e139. https://www. auajournals.org/doi/pdf/10.1016/j.juro.2017.02.3129 